\title{
Induction of apoptosis and suppression of angiogenesis of hepatocellular carcinoma by HS-159, a novel phosphatidylinositol 3-kinase inhibitor
}

\author{
SUN-MI YUN ${ }^{1 *}$, JU-HEE LEE $^{1 *}$, KYUNG HEE JUNG $^{1}$, HYUNSEUNG LEE $^{1}$, \\ SOYOUNG LEE ${ }^{2}$, SUNGWOO HONG ${ }^{2}$ and SOON-SUN HONG ${ }^{1}$ \\ ${ }^{1}$ College of Medicine, Inha University, Jung-gu, Incheon 400-712; ${ }^{2}$ Department of Chemistry, \\ Korea Advanced Institute of Science and Technology (KAIST), Daejeon 305-701, Republic of Korea
}

Received December 18, 2012; Accepted February 15, 2013

DOI: $10.3892 /$ ijo.2013.1912

\begin{abstract}
The phosphatidylinositol 3-kinase (PI3K) pathway plays a central role in cell proliferation and survival in human cancer and is emerging as an attractive therapeutic target. In this study, we synthesized a novel PI3K $\alpha$ inhibitor, HS-159 [N-(5-(3-(3-cyanophenyl)imidazo[1,2-a]pyridin-6-yl)pyridin3 -yl)benzenesulfonamide] and evaluated its anticancer effects on Huh-7 human hepatocellular carcinoma (HCC) cells. HS-159 effectively inhibited the phosphorylation of downstream PI3K effectors such as Akt, mTOR and P70S6 kinases in a dose-dependent manner. This compound also induced apoptosis and increased the fraction of apoptotic cells in the sub- $\mathrm{G}_{1}$ phase as well as the levels of cleaved PARP, caspase-3 and -9 . Furthermore, HS-159 decreased the expression of hypoxia inducible factor- $1 \alpha$ and vascular endothelial growth factor which play important roles in angiogenesis. The antiangiogenic effect of HS-159 was confirmed by the suppression of tube formation and migration of human umbilical vein endothelial cells in vitro. Collectively, our results demonstrate that HS-159 exhibited anticancer activities including the induction of apoptosis and inhibition of angiogenesis by blocking the PI3K/Akt pathway in Huh-7 cells. Therefore, we
\end{abstract}

Correspondence to: Dr Soon-Sun Hong, Department of Biomedical Sciences, College of Medicine, Inha University, 3-ga, Sinheung-dong, Jung-gu, Incheon 400-712, Republic of Korea

E-mail: hongs@inha.ac.kr

Dr Sungwoo Hong, Department of Chemistry, Korea Advanced Institute of Science and Technology (KAIST), Daejeon 305-701, Republic of Korea

E-mail: hongorg@kaist.ac.kr

${ }^{*}$ Contributed equally

Key words: phosphatidylinositol 3-kinase inhibitor, anticancer, apoptosis, angiogenesis, hepatocellular carcinoma suggest that this drug may be potentially used for targeted HCC therapy.

\section{Introduction}

Worldwide, hepatocellular carcinoma (HCC) is the sixth most common cancer and the third most prevalent cause of cancerrelated mortality. HCC is also responsible for over 600,000 deaths annually (1). Although this disease is most prevalent in Asia and Africa, the incidence of HCC is increasing in Europe and the United States (2-5). Due to its asymptomatic nature during the early stages, HCC is often diagnosed at a late stage with a very poor prognosis. Although tumor ablation surgery can be successfully performed in patients with early stages of $\mathrm{HCC}$, the recurrence rate is $\sim 50 \%$ within 3 years (6). Even with relatively aggressive treatments such as systemic chemotherapy, radiotherapy and trans-arterial chemoembolization, the 5-year relative survival rate for patients with HCC is only $7 \%$ (7). Moreover, systemic therapy with classical cytotoxic drugs has been reported to be poorly tolerated and ineffective (8). In particular, sorafenib, a compound globally approved for treating unresectable and advanced cases of HCC, is associated with low response rates and several unwanted side effects such as hypertension, diarrhea and skin reactions on the hands and feet $(9,10)$. Therefore, an effective and well-tolerated pharmaceutical agent for treating advanced HCC is needed.

In recent years, studies of signaling pathways that regulate cancer cell proliferation, angiogenesis, invasion and metastasis have led to the identification of several possible therapeutic targets. In particular, many clinical investigations have indicated that the phosphatidylinositol 3-kinase (PI3K)/ Akt signaling pathway plays an integral role in the regulation of many key cellular processes such as proliferation, growth, survival, differentiation and metabolism. Additionally, this pathway is one of the most commonly activated in various cancers (11-13). PI3K generates a lipid secondary messenger, phosphatidylinositol 3,4,5-triphosphate (PIP3), from phosphatidylinositol 4, 5-diphosphate (PIP2) and then leads to Akt activation. Akt subsequently phosphorylates mTOR and several other proteins. mTOR is a serine/threonine protein 
kinase that exists as two functional complexes: mTORC1 and mTORC2 $(14,15)$. This kinase promotes cell growth and cell cycle progression by phosphorylating several translational regulators such as P70S6 kinase (P70S6K).

Abnormal activation of the PI3K/Akt pathway is observed in $~ 50 \%$ of patients with HCC (16). Additionally, Akt phosphorylation is involved in early HCC recurrence and poor prognosis (17) and 23\% of HCC patients have elevated levels of Akt phosphorylation on $\mathrm{Ser}^{473}$ (18). Concurrently, total mTOR expression has been found to be increased in 5\% of HCC cases and elevated levels of phosphorylated mTOR have been reported in $15 \%$ of HCC patients. In addition, phosphorylated (p)-mTOR positively correlates with increased expression of S6K, which is found in 45\% of HCC cases (19). For this reason, the PI3K/Akt/mTOR pathway has emerged as a key therapeutic target and seems to offer a promising strategy for treating patient with HCC.

Although several PI3K/Akt pathway inhibitors have been identified, clinical trials for these agents are only in the early stages. In vivo applications have also been limited due to problems with inhibitor stability, solubility and toxicity (20-23). To discover a new structural class of PI3K inhibitors, we used a pharmacophore-directed design. As a result, we recently identified a novel scaffold belonging to the imidazopyridine family that acts as a PI3K/mTOR inhibitor (24). Based on this finding, we designed, synthesized and screened a new series of imidazo[1,2-a]pyridine derivatives. Among these, a new compound, N-(5-(3-(3-cyanophenyl)imidazo[1,2-a]pyridin6-yl)pyridin-3-yl)benzenesulfonamide (HS-159) was found to be the most potent PI3K inhibitor. In the present study, we determined whether HS-159 has anticancer effects against $\mathrm{HCC}$ and explored the molecular mechanism involved in this process.

\section{Materials and methods}

In vitro PI3K activity assay. Active PI3K $\alpha(100 \mathrm{ng})$ was preincubated with various doses of HS-159 or LY294002 for 5 min in kinase reaction buffer (25 mM MOPS, pH 7.0; $5 \mathrm{mM} \mathrm{MgCl}_{2}$ and $1 \mathrm{mM}$ EGTA) and $10 \mu \mathrm{g} \mathrm{L}-\alpha$-phosphatidylinositol. The L- $\alpha$-phosphatidylinositol was sonicated in water for $20 \mathrm{~min}$ before being added to the reaction to facilitate micelle formation. The reaction was initiated by adding $10 \mu \mathrm{M}$ ATP and allowed to run for $180 \mathrm{~min}$ at room temperature. To terminate the kinase reaction, an equal volume of Kinase-Glo ${ }^{\circledR}$ buffer (Promega, Madison, WI) was added. After 10 min, luminescence of the plates was measured with a GloMax plate reader.

Cell lines. Human liver cancer (HepG2, Huh-7 and Hep3B) cells were purchased from the Korean Cell Line Bank (KCLB, Seoul, Korea). Huh-7 cells were cultured in Roswell Park Memorial Institute 1640 (RPMI-1640) medium with 10\% fetal bovine serum (FBS) and 1\% penicillin/streptomycin. HepG2 and Hep3B cells were cultured in Dulbecco's modified Eagle's medium (DMEM) supplemented with $10 \%$ fetal bovine serum (FBS) and $1 \%$ penicillin/streptomycin. Human umbilical vein endothelial cells (HUVECs) were grown in a gelatin-coated $75-\mathrm{cm}^{2}$ flask with M199 medium containing $20 \mathrm{ng} / \mathrm{ml}$ basic fibroblast growth factor (bFGF), $100 \mathrm{U} / \mathrm{ml}$ heparin and $20 \%$ FBS. All cell cultures were maintained at $37^{\circ} \mathrm{C}$ in a $\mathrm{CO}_{2}$ incubator with a controlled humidified atmosphere composed of $95 \%$ air and $5 \% \mathrm{CO}_{2}$.

Cell viability assay. Cell viability was evaluated using a 3-(4,5-dimethylthiazol-2-yl)-2, 5-diphenyltetrazolium bromide (MTT) assay. Briefly, cells were seeded at a density of $1 \times 10^{4}$ cells/well in a 96-well plate and incubated for $24 \mathrm{~h}$. The medium was then removed and the cells were treated with either DMSO as a control or various concentrations $(0.1-10 \mu \mathrm{M})$ of HS-159 for $48 \mathrm{~h}$ at $37^{\circ} \mathrm{C}$. Next, $10 \mu \mathrm{l}$ of MTT solution $(2 \mathrm{mg} /$ $\mathrm{ml})$ was added to each well and the plate was incubated for another $4 \mathrm{~h}$ at $37^{\circ} \mathrm{C}$. The medium was then removed and the formazan crystals that had formed were dissolved in DMSO (200 $\mu \mathrm{l} /$ well) with constant shaking for $5 \mathrm{~min}$. Absorbance of the solution was then measured with a microplate reader at $540 \mathrm{~nm}$. This assay was conducted in triplicate.

Western blotting. Total cellular proteins were extracted with lysis buffer containing $1 \%$ Triton X-100, $1 \%$ Nonidet P-40 and a $1 \%$ protease and phosphatase inhibitor cocktail containing aprotinin $(10 \mathrm{mg} / \mathrm{ml})$, leupeptin $(10 \mathrm{mg} / \mathrm{ml}$; ICN Biomedicals, Asse-Relegem, Belgium), phenylmethylsulfonyl fluoride $(1.72 \mathrm{mM}), \mathrm{NaF}(100 \mathrm{mM}), \mathrm{NaVO}_{3}(500 \mathrm{mM})$ and $\mathrm{Na}_{4} \mathrm{P}_{2} \mathrm{O}_{7}$ (500 mg/ml; Sigma-Aldrich, St. Louis, MO). The proteins were separated by sodium dodecyl sulfate-polyacrylamide gel electrophoresis (SDS-PAGE) and transferred onto nitrocellulose membranes. The blots were incubated with the appropriate primary antibodies followed by incubation with secondary antibodies conjugated to horseradish peroxidase. Antibody binding was detected with an enhanced chemiluminescence reagent (Amersham Biosciences). Antibodies against p-mTOR $\left(\operatorname{Ser}^{2448}\right)$, mTOR, p-Akt $\left(\operatorname{Ser}^{473}\right)$, Akt, p-P70S6K $\left(\mathrm{Thr}^{389}\right)$, P70S6K, PARP, cleaved caspase-3, hypoxia inducible factor-1 $\alpha$ (HIF-1 $\alpha$ ), vascular endothelial growth factor (VEGF) and $\beta$-actin were purchased from Cell Signaling Technology Inc. (Danvers, MA).

Immunofluorescence microscopy. Huh-7 cells were plated on 18-mm cover glasses in RPMI-1640 medium and incubated for $24 \mathrm{~h}$ at $37^{\circ} \mathrm{C}$ so that $\sim 70 \%$ confluence was reached. The cells were then incubated in the presence or absence of $10 \mu \mathrm{M}$ HS-159, washed twice with PBS and fixed in an acetic acid: ethanol solution $(1: 2, \mathrm{v} / \mathrm{v})$ for $10 \mathrm{~min}$ at $-20^{\circ} \mathrm{C}$. The cells were blocked in $1.5 \%$ horse serum in PBS for $30 \mathrm{~min}$ at room temperature and then incubated overnight at $4{ }^{\circ} \mathrm{C}$ with primary antibodies against p-Akt, p-mTOR and p-P70S6K (Cell Signaling) in a humidified chamber. After washing twice with PBS, the cells were then incubated with rabbit TRITC secondary antibody (1:100, Dianova, Germany) for $1 \mathrm{~h}$ at room temperature. The cells were also stained with 4, 6-diamidino2-phenylindole (DAPI) to visualize the nuclei. The slides were then washed twice with PBS and covered with fluorescent mounting medium (Dako North America Inc., Carpinteria, CA) before viewing with a confocal laser scanning microscope (Olympus, Tokyo, Japan).

Cell cycle analysis. Huh-7 cells were plated in 100-mm culture dishes with RPMI-1640 medium at $\sim 70 \%$ confluence and incubated for $24 \mathrm{~h}$ at $37^{\circ} \mathrm{C}$. The next day, the cells were treated with either DMSO as a control or various concentra- 
tions $(0.01-10 \mu \mathrm{M})$ of HS-159. Floating and adherent cells were collected and fixed overnight in cold $70 \%$ ethanol at $4^{\circ} \mathrm{C}$. After washing with PBS, the cells were subsequently stained with $50 \mu \mathrm{g} / \mathrm{ml}$ propidium iodide (PI) and $100 \mu \mathrm{g} /$ $\mathrm{ml}$ RNase A for $1 \mathrm{~h}$ at room temperature in the dark. Flow cytometry was then performed with a FACSCalibur flow cytometer (Becton-Dickinson, San Jose, CA) to determine the percentage of cells in specific phases of the cell cycle (sub- $\mathrm{G}_{1}, \mathrm{G}_{0} / \mathrm{G}_{1}, \mathrm{~S}$ and $\mathrm{G}_{2} / \mathrm{M}$ ). The data were analyzed using FlowJo software (Tree Star, Inc.). All the experiments were performed in triplicate.

DAPI staining and terminal deoxynucleotidyltransferasemediated nick end labeling (TUNEL). Huh-7 cells were plated on an 18-mm cover glass with RPMI-1640 medium at $~ 70 \%$ confluence and incubated for $24 \mathrm{~h}$ at $37^{\circ} \mathrm{C}$. The cells were then incubated in the presence or absence of $10 \mu \mathrm{M}$ HS-159 for $24 \mathrm{~h}$. The cells were then fixed in cold $2 \%$ para-formaldehyde (PFA), washed with PBS and stained with $2 \mu \mathrm{g} / \mathrm{ml}$ of DAPI (Sigma-Aldrich) for $20 \mathrm{~min}$ at $37^{\circ} \mathrm{C}$. The stained cells were examined under a fluorescence microscope for evidence of nuclear fragmentation. A TUNEL assay was subsequently performed using a commercial kit (Chemicon, Temecula, CA) according to the manufacturer's instructions.

Measurement of mitochondrial membrane potential $\left(\psi_{m}\right)$. Mitochondrial membrane potential was assessed with a mitochondria staining kit (MitoPT, Immunohistochemistry Technologies, Bloomington, MN) using 5, 5', 6, 6'-tetrachloro-1, 1', 3, 3'-tetraethylbenzimidazol-carbocyanine iodide (JC-1), which indicates potential-dependent accumulation in mitochondria. Huh-7 cells were plated on 18-mm cover glass in RPMI-1640 medium and incubated for $24 \mathrm{~h}$ at $3^{\circ} \mathrm{C}$. When confluence reached $\sim 70 \%$, the cells were incubated in the presence or absence of $10 \mu \mathrm{M}$ HS- 159 at $37^{\circ} \mathrm{C}$ for $6 \mathrm{~h}$. Next, $100 \mu \mathrm{l}$ of a JC-1 solution ( $12.5 \mu \mathrm{g} / \mathrm{ml}$ final concentration) was added to each well and the plate was incubated for $30 \mathrm{~min}$ at $3^{\circ} \mathrm{C}$. After washing twice with PBS, the cells were stained with DAPI to visualize the nuclei. The slides were then washed twice with PBS and covered with DABCO before viewing with a confocal laser scanning microscope (Olympus). The results [green/red $(\mathrm{G} / \mathrm{R})$ fluorescence ratio] were expressed as a percentage of the control.

Capillary tube formation assay. Matrigel (10 mg/ml, $200 \mu \mathrm{l}$; BD Biosciences) was polymerized for $30 \mathrm{~min}$ at $37^{\circ} \mathrm{C}$. HUVECs were suspended at a density of $2.5 \times 10^{5}$ cells/well in M199 medium supplemented with 5\% FBS. Aliquots $(0.2 \mathrm{ml})$ of the cell suspension were added to each well coated with Matrigel and incubated with or without different concentrations of HS-159 for $24 \mathrm{~h}$ at $37^{\circ} \mathrm{C}$. Morphological changes of the cells and tube formation were observed with a phase-contrast microscope. The cells were captured at magnification x 200 .

Wound migration assay. HUVECs were plated on 60-mm culture dishes at $\sim 90 \%$ confluence. A razor blade was then used to create a wound $2 \mathrm{~mm}$ in width in the cell monolayer and the injury line was marked. After wounding, the detached cells were removed with serum-free medium and the remaining HUVECs were further incubated in M199 medium supplemented with 5\% FBS, 1 mM thymidine (Sigma-Aldrich) and HS-159 $(0.5 \mu \mathrm{M})$. The cells were allowed to migrate for $18 \mathrm{~h}$ before being rinsed with serum-free medium and fixed in absolute methanol. Cell migration was quantitated by counting the number of cells that had moved beyond the injury line.

Statistical analysis. Data are expressed as the mean \pm standard deviation (SD). Statistical analysis was performed using an ANOVA and unpaired Student's t-test. P-values $\leq 0.05$ were considered statistically significant. All calculations were performed using SPSS software for the MS Windows operating system (version 10.0; SPSS, Chicago, IL).

\section{Results}

HS-159 inhibits PI3K activity. A new PI3K $\alpha$ inhibitor, HS-159 (N-(5-(3-(3-cyanophenyl)imidazo[1,2-a]pyridin-6-yl)pyridin3 -yl)benzenesulfonamide) was synthesized as described in our previous study (Fig. 1A) (25). Three-dimensional (3D) coordinates in the X-ray crystal structure of PI3K $\alpha$ in the resting form (PDB code: 2RD0) were selected as the receptor model for docking simulations. After removing the solvent molecules, hydrogen atoms were added to each protein atom. We used the Auto Dock program for studying docking between PI3K $\alpha$ and HS-159 because the outperformance of its scoring function over those of the others had been shown in several target proteins. The predicted binding mode of HS-159 in the ATP-binding site of PI3K $\alpha$ is shown in Fig. 1B. The imidazopyridine of HS-159 maintained stable hydrogenbonding in the hinge region (Val851). The pyridyl group was anchored by hydrogen bonds to Asp933 and interacted with gatekeeper residue Tyr836. Two stable hydrogen bonds were established between the cyano group of C3 and Thr856. These hydrogen bonds were received from the enzyme and seemed to play a crucial role as an anchor for HS-159 binding. HS-159 could be further stabilized in the ATP-binding site by forming hydrophobic interactions with Met772, Pro778, Lys802, Val850, Ser854, Gln859 and Ile932. Judging from the overall structural features derived from our docking simulations, the inhibitory activity of HS-159 is likely to stem from multiple hydrogen bonds and hydrophobic interactions simultaneously established in the ATP-binding site of PI3K $\alpha$. We also found that HS-159 more strongly inhibited PI3K $\alpha$ activity $\left(\mathrm{EC}_{50} 1.892 \mathrm{nM}\right)$ compared to LY294002, a conventional specific PI3K inhibitor ( $\mathrm{EC}_{50} 488.8 \mathrm{nM}$, Fig. 1C).

HS-159 inhibits the PI3K/Akt signaling pathway in Huh-7 cells. Since HS-159 inhibited PI3K $\alpha$ activity, we next determined whether this drug also affected downstream signal transduction factors that promote PI3K-mediated cell survival. When Huh-7 cells were treated with various concentrations of HS-159 for $6 \mathrm{~h}$, the phosphorylation of Akt and its downstream components such as mTOR and P70S6K was effectively suppressed in a dose-dependent manner (Fig. 2A). We further assessed the effect of HS-159 on Akt, mTOR and P70S6K using a fluorescent imaging system. Results from this assay again showed that HS-159 strongly suppressed phosphorylation of these proteins in Huh-7 cells, similar to the western blotting results (Fig. 2B). 
A

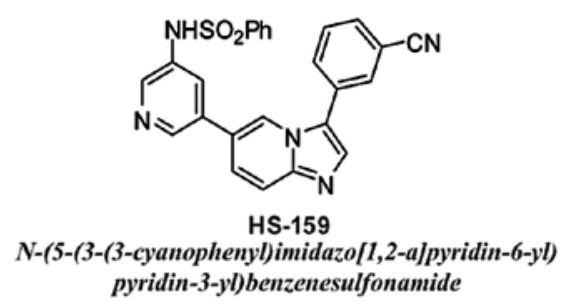

B

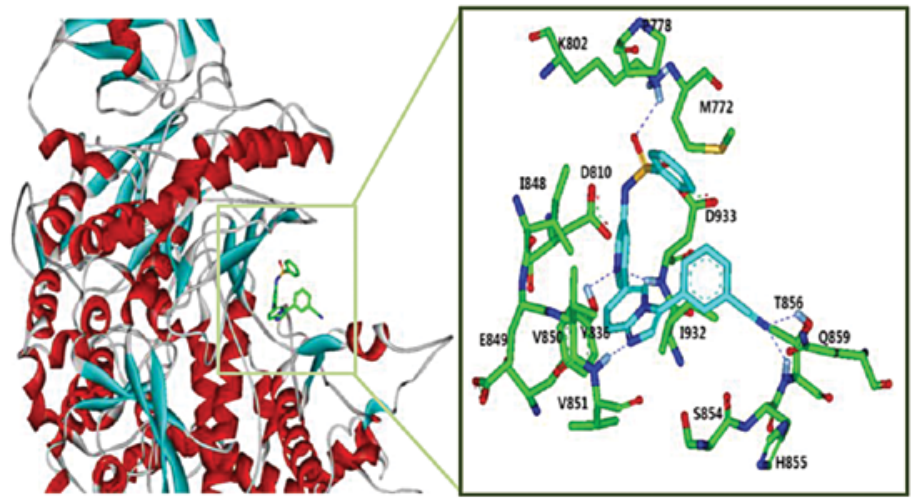

C

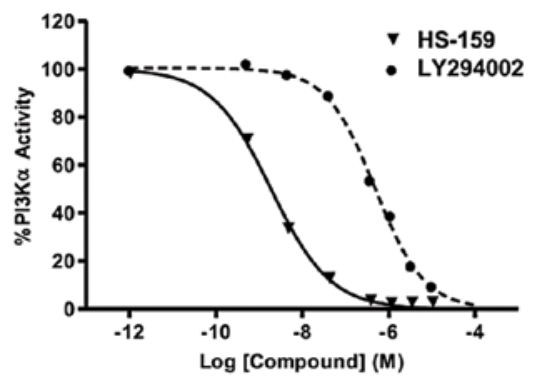

\begin{tabular}{|c|c|c|}
\hline \multirow{2}{*}{$E_{50}$} & $H S-159$ & LY294002 \\
\cline { 2 - 3 } & $1.892 \mathrm{nM}$ & $488.8 \mathrm{nM}$ \\
\hline
\end{tabular}

Figure 1. Chemical structure and characterization of HS-159. (A) Chemical structure of HS-159, [N-(5-(3-(3-cyanophenyl)imidazo[1,2-a]pyridin-6-yl)pyridin3-yl)benzenesulfonamide]. (B) Docking mode of HS-159 according to the PI3Ka homology model based on PI3K $\gamma$ crystal structures. (C) Inhibition of PI3Ka by HS-159 or LY294002 in silico.

HS-159 inhibits the growth of HCC cells. Next, we further evaluated the anti-proliferative effects of HS-159 on HCC cells using an MTT assay. Huh-7, HepG2 and Hep3B cells were exposed to various concentrations (0.1-10 $\mu \mathrm{M})$ of HS-159 for $48 \mathrm{~h}$. HS-159 markedly reduced viability of the three HCC cell lines in a dose-dependent manner (Fig. 3). These results indicated that HS-159 exerts potent anti-proliferative effects on HCC cells.

HS-159 induces apoptosis in Huh-7 cells. Cell apoptosis and growth are correlated with cell cycle progression (26). In the present study, HS-159 $(0.1-10 \mu \mathrm{M})$ inhibited the growth of HCC cells in a dose-dependent manner (Fig. 3). Thus, we performed flow cytometry to monitor changes of the cell cycle profile induced by HS-159. Data from this analysis revealed that treatment with 5 and $10 \mu \mathrm{M}$ HS-159 increased the number of cells in a sub- $\mathrm{G}_{1}$ stage, indicative of apoptosis and decreased the fraction of cells in the $G_{0} / G_{1}$ phase in Huh-7 cells (Fig. 4A).
HS-159-induced apoptosis was also evaluated by DAPI and TUNEL staining to characterize nuclear morphology. As shown in Fig. 4B, cells treated with $10 \mu \mathrm{M}$ HS-159 had morphological features characteristic of apoptotic cells such as bright nuclear condensation and perinuclear apoptotic bodies observed with DAPI staining. HS-159-induced apoptosis was also confirmed by detecting DNA fragmentation using a TUNEL assay. In addition, we performed JC-1 staining to measure the effect of HS-159 on changes in mitochondrial membrane potential that correlate with the intrinsic pathway of apoptosis. As shown in Fig. 4C, the cytoplasm of control cells showed heterogeneous staining with both red and green fluorescence coexisting in the same cells. Consistent with mitochondrial localization, red fluorescence (corresponding to high mitochondrial membrane potential, $\psi_{\mathrm{m}}$ ) was mostly found in granular structures distributed throughout the cytoplasm. Treatment with $10 \mu \mathrm{M}$ HS-159 decreased the red fluorescence while frequent clusters of mitochondria were still observed. HS-159 induced marked changes 
A

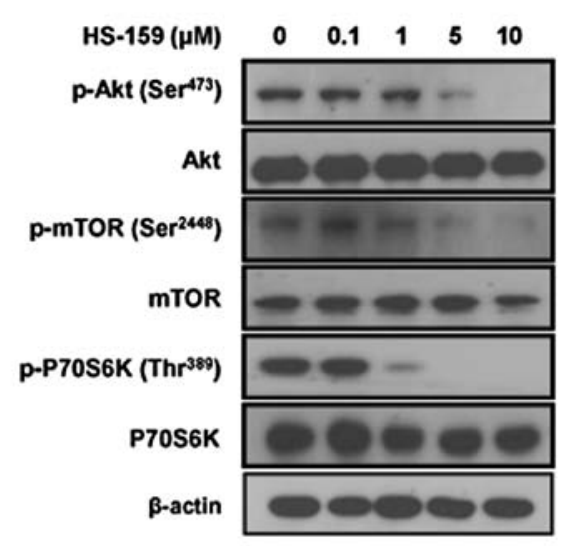

B

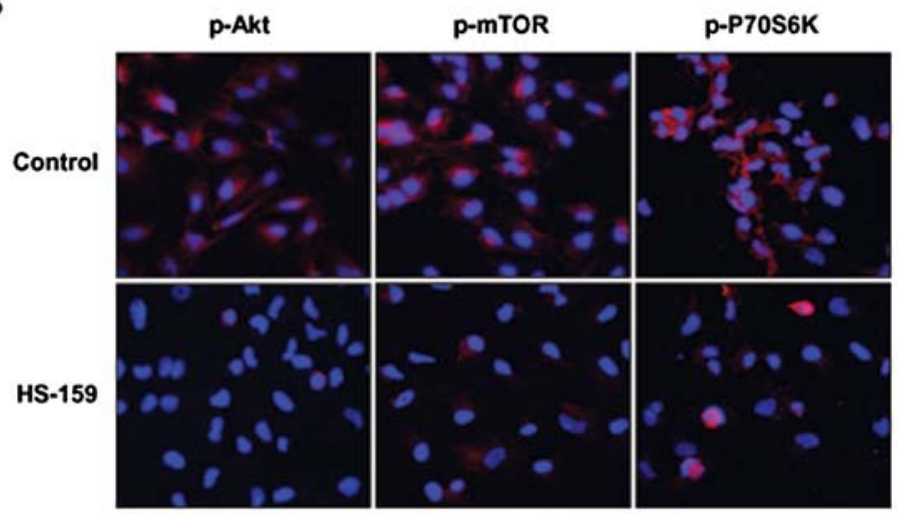

Figure 2. Effect of HS-159 on PI3K/Akt signaling in Huh-7 cells. (A) Cells were treated with various concentrations ( $0.1-10 \mu \mathrm{M})$ of HS-159 for $6 \mathrm{~h}$. The protein expression and phosphorylation of Akt, mTOR and P70S6K were analyzed by western blotting. (B) Huh-7 cells were treated with or without $10 \mu \mathrm{M}$ HS-159. p-Akt, p-mTOR and p-P70S6K were detected by immunostaining and confocal microscopy. DAPI was used to counterstain the nucleus. Images were taken at magnification $\mathrm{x} 400$.
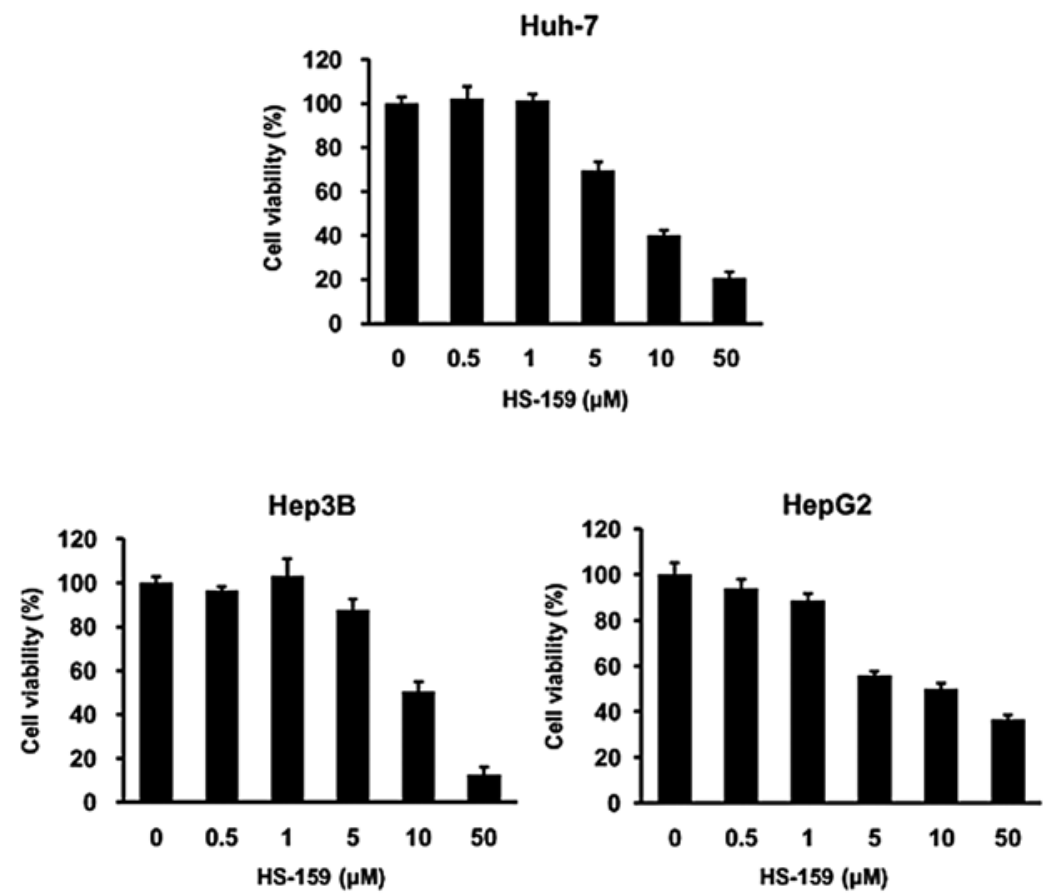

Figure 3. Effect of HS-159 on the proliferation of human HCC cells. Inhibitory effect of HS-159 on the proliferation of Huh-7, HepG2 and Hep3B cells was assessed with an MTT assay. Results are expressed as the percent cell proliferation relative to the proliferation of the control. Each value represents the mean \pm SD of triplicate wells. 
A
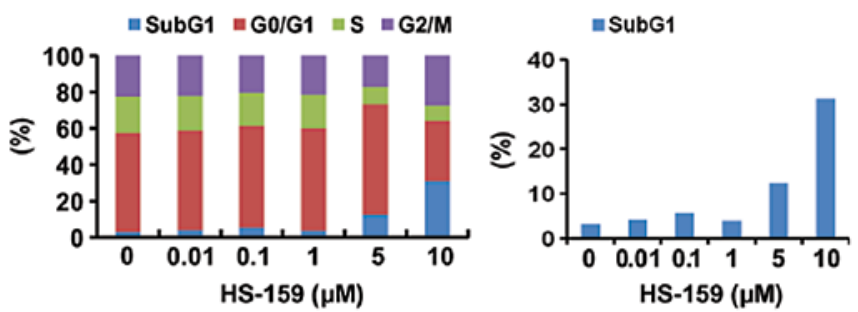

B

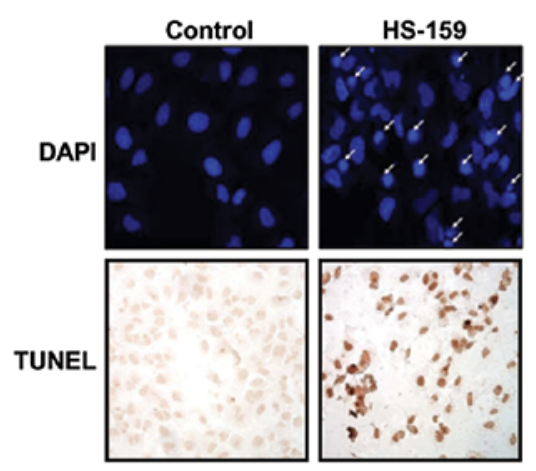

C
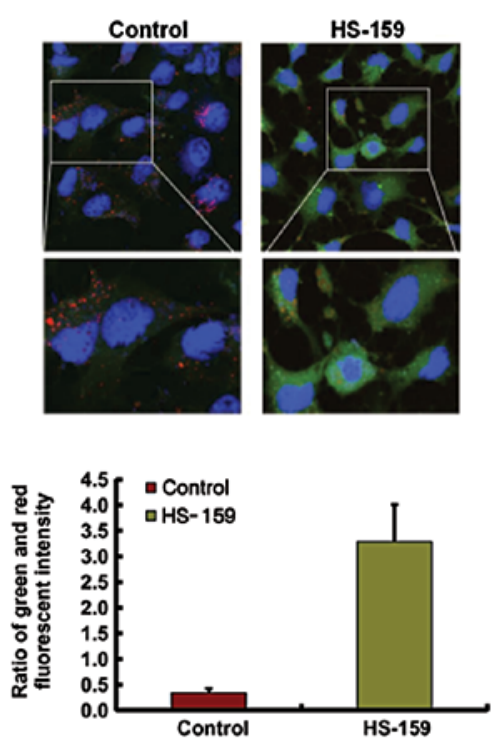

D

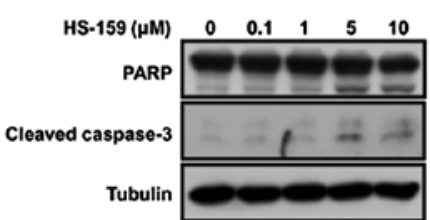

Figure 4. Effect of HS-159 on apoptosis of Huh-7 cells. (A) Huh-7 cells were treated with HS-159 $(0.01-10 \mu \mathrm{M})$ for $24 \mathrm{~h}$, stained with PI and analyzed with a FACSCalibur flow cytometer. Quantification of PI staining is presented as percentages corresponding to cell cycle distribution. (B) Huh-7 cells treated with or without HS-159 $(10 \mu \mathrm{M})$ were evaluated by DAPI staining and a TUNEL assay. (C) Huh-7 cells were treated with HS-159 $(10 \mu \mathrm{M})$ for $6 \mathrm{~h}$. Mitochondrial membrane potential was measured by JC-1 staining and analyzed with a fluorescence microplate reader. The results (G/R ratio) are expressed as the percentage of cells treated with HS-159. Data are expressed as the mean \pm SD of triplicate wells. (D) The levels of cleaved caspase-3 and PARP in cells treated with the indicated doses of HS-159 for $24 \mathrm{~h}$ were measured by western blotting. in $\psi_{\mathrm{m}}$ as evident from the disappearance of red fluorescence or increased green fluorescence in most cells. We next performed western blotting to evaluate the activation of caspase- 3 and PARP after treatment with HS-159. As expected, HS-159 increased the levels of cleaved caspase-3 and PARP in Huh-7 cells in a dose-dependent manner (Fig. 4D). Taken together, these results showed that HS-159 induces apoptotic cell death in Huh-7 cells.

$H S-159$ inhibits the expression of HIF-1 $\alpha$ and VEGF in Huh-7 cells. A low oxygen level is characteristic of solid tumors and a negative prognostic factor for cancer patient survival. The response of cancer cells to hypoxia not only drives neo-angiogenesis, but also enhances cell survival and malignant phenotype development. HIF-1 $\alpha$ is a major regulator of cellular adaptive responses to hypoxia as well as a major transcriptional modulator of angiogenic factors such as VEGF (27). We therefore evaluated the effect of HS-159 on the expression of HIF-1 $\alpha$ and VEGF in Huh-7 cells under hypoxia conditions. The cells were treated with various concentrations of HS-159 cultured for $16 \mathrm{~h}$ with $100 \mu \mathrm{M}$ $\mathrm{CoCl}_{2}$ for mimic hypoxic conditions. As shown in Fig. 5A, the expression of HIF-1 $\alpha$ and VEGF was increased after exposure to hypoxia and subsequently suppressed by HS-159 treatment, respectively.

HS-159 suppresses angiogenesis. In endothelial cells, PI3K/ Akt signaling actively mediates processes associated with angiogenesis including cell migration and capillary tube formation (28). Therefore, we performed capillary tube formation and migration assays to determine whether HS-159 suppresses the angiogenic activity of HUVECs. HS-159 inhibited the formation of vessel-like structures resulting from HUVEC elongation and alignment (Fig. 5B). HS-159 also markedly inhibited cell migration (Fig. $5 \mathrm{C}$ ). These results indicate that HS-159 is a potential anti-angiogenic reagent that inhibits the tube formation and migration of HUVECs.

\section{Discussion}

Many clinical studies have indicated that hyper-activation of the PI3K/Akt pathway plays a critical role in the pathogenesis of various human cancers. Consequently, the PI3K/Akt pathway has emerged as an important therapeutic target for anticancer drug development. Several inhibitors targeting this pathway have been recently developed and some are being evaluated in clinical trials $(29,30)$. These compounds have a wide variety of targets and, include pan-PI3K, isoformspecific PI3K, dual PI3K-mTOR, mTOR catalytic site and Akt inhibitors (23,31-33). Nevertheless, an optimal therapeutic strategy for targeting the PI3K/Akt pathways in cases of HCC has not been identified. In an effort to develop potent PI3K inhibitors, we screened a large number of novel imidazopyridine derivatives. Among them HS-159 acted as a specific PI3K inhibitor, which more strongly inhibited PI3K $\alpha$ activity $\left(\mathrm{EC}_{50} 1.892 \mathrm{nM}\right)$ than LY294002, a conventional PI3Kspecific inhibitor $\left(\mathrm{EC}_{50} 488.8 \mathrm{nM}\right)$. In addition it significantly suppressed proliferation and angiogenesis as well as induced apoptosis by blocking the PI3K/Akt signaling pathway in HCC cells. 
A

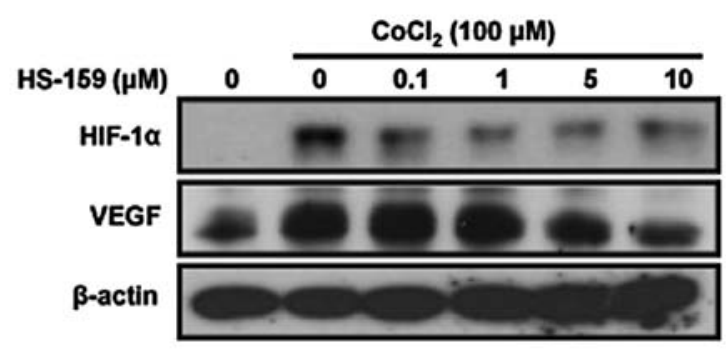

B

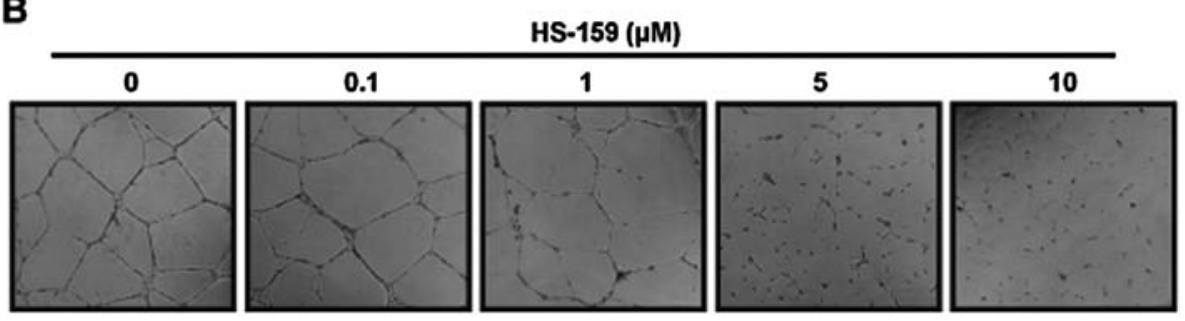

C
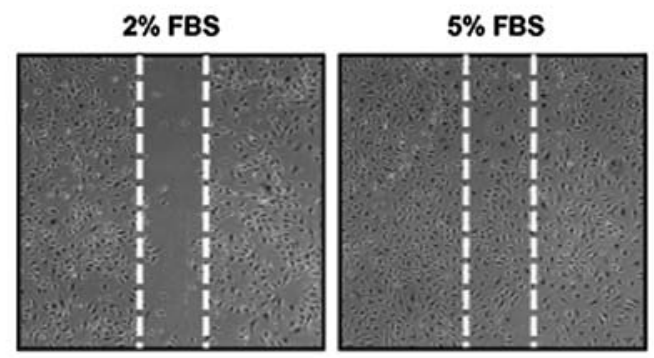

$5 \%$ FBS + HS-159

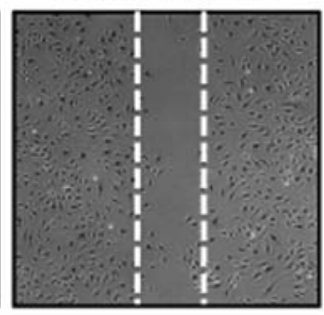

Figure 5. Effect of HS-159 on angiogenesis. (A) Expression of HIF-1 $\alpha$ in hypoxic Huh-7 cells treated with HS-159. (B) Effects of HS-159 on HUVEC tube formation in vitro. HUVECs were plated on Matrigel (200 $\mu \mathrm{l} /$ well) and treated with different concentrations of HS-159. Capillary tube formation was assessed after $24 \mathrm{~h}$. Morphological changes of the cells and tube formation were observed under a phase-contrast microscope and caprutred at magnification x 200 . (C) Effects of HS-159 $(0.5 \mu \mathrm{M})$ on cell migration in vitro. HUVECs were plated at $\sim 90 \%$ confluence and the cell monolayer was scratched with a razor blade.

Akt is considered the most important signaling factor in the PI3K pathway as it regulates various substrates affecting processes that control cell growth and survival (34). It was also reported that Akt phosphorylation on $\mathrm{Ser}^{473}$ is associated with poor prognosis in patients with different types of solid tumors including those in the pancreas, liver, prostate and breast (35). In our western blotting and immunofluorescent studies, HS-159 was found to effectively suppress the phosphorylation of downstream PI3K effectors including Akt, mTOR and P70S6K dose-dependently in HCC cells. Considering that the $\mathrm{PI} 3 \mathrm{~K} /$ Akt pathway is important for cell growth and progression, we also tested whether HS-159 inhibited the survival of three HCC cell lines. HS-159 inhibited the growth of all three cell lines in a dose-dependent manner. Thus, we suggest that HS-159 prevents cell growth by blocking the PI3K/Akt pathway in HCC cells.

Cell cycle arrest in tumor cells is a major indicator of anticancer activity. Additionally, cell cycle dysregulation has been implicated in tumor development and proliferation characteristic of different cancers, including HCC (30). Thus, we analyzed cell cycle changes following treatment with HS-159. We found that HS-159 induced cell cycle arrest during the $\mathrm{G}_{0} / \mathrm{G}_{1}$ phase. We also observed that the anti-proliferative activity of HS-159 was associated with the induction of apoptosis in Huh-7 cells. This was indicated by elevated levels of cleaved caspase-3 and PARP as well as increased number of TUNEL-positive cells. The alteration of mitochondrial membrane potential induces the release of cytochrome $\mathrm{c}$ from mitochondria into the cytosol and is associated with caspase-3 activation (36). We therefore monitored changes of mitochondrial membrane potential following treatment with HS-159. Our results showed that treatment with HS-159 disrupted the mitochondrial membrane potential in Huh-7 cells. Overall, these data suggest that HS-159 induced apoptotic cell death through activation of the intrinsic apoptotic pathway.

Rapid tumor cell proliferation in a stable vascular system leads to the development of hypoxia in almost all solid tumors (26). Because the liver is a highly vascular organ that depends on angiogenesis for cellular regeneration, angiogenesis may be specifically targeted as a novel therapeutic approach for treating HCC (37). Hypoxia in many solid tumors increases the expression of major angiogenic factors such as HIF-1 $\alpha$ and VEGF to promote neo-angiogenesis $(38,39)$. Additionally, it has been reported that PI3K signaling regulates HIF-1 $\alpha$ and VEGF expression $(40,41)$. We thus assessed the effect of HS-159 on expression of these two angiogenic factors. 
As expected, HS-159 significantly reduced the expression of both HIF-1 $\alpha$ and VEGF under hypoxic conditions induced by $\mathrm{CoCl}_{2}$ in Huh-7 cells. The activation of endothelial cells by angiogenic processes results in cell proliferation and migration as well as cord tube formation for the creation of new microvessels (42). We performed tube formation and migration assays to study the effect of HS-159 on HUVECs. HS-159 significantly inhibited HUVEC tube formation as well as migration. Overall, our data suggest that HS-159 may be a potent anti-angiogenic agent.

In conclusion, our study demonstrated that HS-159 is a specific PI3K inhibitor and exerts potent anticancer effects against HCC cells. Additionally, blocking the PI3K/Akt pathway with HS-159 inhibited cell proliferation and angiogenesis and induced apoptosis of HCC cells. These finding suggest that HS-159 is a novel anticancer agent with the potential for treating patients with $\mathrm{HCC}$ and other diseases associated with dyregulated PI3K signaling.

\section{Acknowledgements}

This study was supported by the Korean Health Technology R\&D Project (A110862, A120266), Ministry of Health and Welfare, the National Research Foundation of Korea (NRF) funded by the Ministry of Education, Science and Technology (NRF-2012-0002988, 2012R1A2A2A01045602, 20110016436, 2011-0020322, 2012-0003009).

\section{References}

1. Llovet JM, Burroughs A and Bruix J: Hepatocellular carcinoma. Lancet 362: 1907-1917, 2003.

2. Poon RT, Fan ST, Lo CM, Liu CL and Wong J: Intrahepatic recurrence after curative resection of hepatocellular carcinoma long-term results of treatment and prognostic factors. Ann Surg 229: 216-222, 1999

3. El-Serag HB and Mason AC: Rising incidence of hepatocellular carcinoma in the United States. N Engl J Med 340: 745-750, 1999.

4. Llovet JM and Bruix J: Novel advancements in the management of hepatocellular carcinoma in 2008. J Hepatol 48 (Suppl 1): S20-S37, 2008.

5. Bruix J and Sherman M: Management of hepatocellular carcinoma. Hepatology 42: 1208-1236, 2005.

6. Mulcahy MF: Management of hepatocellular cancer. Curr Treat Options Oncol 6: 423-435, 2005.

7. Bosch FX, Ribes J, Diaz M and Cleries R: Primary liver cancer: worldwide incidence and trends. Gastroenterology 127: S5-S16, 2004

8. Verslype C, Van Cutsem E, Dicato M, Arber N, Berlin JD, Cunningham D, De Gramont A, Diaz-Rubio E, Ducreux M, Gruenberger T, Haller D, Haustermans K, Hoff P, Kerr D, Labianca R, Moore M, Nordlinger B, Ohtsu A, Rougier P, Scheithauer W, Schmoll HJ, Sobrero A, Tabernero J and van de Velde C: The management of hepatocellular carcinoma. Current expert opinion and recommendations derived from the 10th World Congress on Gastrointestinal Cancer, Barcelona, 2008. Ann Oncol 20 (Suppl 7): vii1-vii6, 2009.

9. Cheng AL, Kang YK, Chen Z, Tsao CJ, Qin S, Kim JS, Luo R, Feng J, Ye S, Yang TS, Xu J, Sun Y, Liang H, Liu J, Wang J, Tak WY, Pan H, Burock K, Zou J, Voliotis D and Guan Z: Efficacy and safety of sorafenib in patients in the Asia-Pacific region with advanced hepatocellular carcinoma: a phase III randomised, double-blind, placebo-controlled trial. Lancet Oncol 10: 25-34, 2009.

10. Kim R, Byrne MT, Tan A and Aucejo F: What is the indication for sorafenib in hepatocellular carcinoma? A clinical challenge. Oncology 25: 283-295, 2011.

11. Yap TA, Garrett MD, Walton MI, Raynaud F, de Bono JS and Workman P: Targeting the PI3K-AKT-mTOR pathway: progress, pitfalls and promises. Curr Opin Pharmacol 8: 393-412, 2008.
12. Ward CS, Venkatesh HS, Chaumeil MM, Brandes AH, Vancriekinge M, Dafni H, Sukumar S, Nelson SJ, Vigneron DB, Kurhanewicz J, James CD, Haas-Kogan DA and Ronen SM: Noninvasive detection of target modulation following phosphatidylinositol 3-kinase inhibition using hyperpolarized 13C magnetic resonance spectroscopy. Cancer Res 70: 1296-1305, 2010.

13. Fry MJ: Phosphoinositide 3-kinase signalling in breast cancer: how big a role might it play? Breast Cancer Res 3: 304-312, 2001.

14. Dunlop EA and Tee AR: Mammalian target of rapamycin complex 1: signalling inputs, substrates and feedback mechanisms. Cell Signal 21: 827-835, 2009.

15. Sparks CA and Guertin DA: Targeting mTOR: prospects for mTOR complex 2 inhibitors in cancer therapy. Oncogene 29: 3733-3744, 2010.

16. Vivanco I and Sawyers CL: The phosphatidylinositol 3-Kinase AKT pathway in human cancer. Nat Rev Cancer 2: 489-501, 2002.

17. Nakanishi K, Sakamoto M, Yamasaki S, Todo S and Hirohashi S: Akt phosphorylation is a risk factor for early disease recurrence and poor prognosis in hepatocellular carcinoma. Cancer 103: 307-312, 2005.

18. Boyault S, Rickman DS, de Reyniès A, Balabaud C, Rebouissou S, Jeannot E, Hérault A, Saric J, Belghiti J, Franco D, Bioulac-Sage P, Laurent-Puig P and Zucman-Rossi J: Transcriptome classification of HCC is related to gene alterations and to new therapeutic targets. Hepatology 45: 42-52, 2007.

19. Sahin F, Kannangai R, Adegbola O, Wang J, Su G and Torbenson M: mTOR and P70 S6 kinase expression in primary liver neoplasms. Clin Cancer Res 10: 8421-8425, 2004.

20. Powis G, Bonjouklian R, Berggren MM, Gallegos A, Abraham R, Ashendel C, Zalkow L, Matter WF, Dodge J, Grindey G and Vlahos CJ: Wortmannin, a potent and selective inhibitor of phosphatidylinositol-3-kinase. Cancer Res 54: 2419-2423, 1994.

21. Vlahos CJ, Matter WF, Hui KY and Brown RF: A specific inhibitor of phosphatidylinositol 3-kinase, 2-(4-morpholinyl)-8phenyl-4H-1-benzopyran-4-one (LY294002). J Biol Chem 269: 5241-5248, 1994.

22. West KA, Castillo SS and Dennis PA: Activation of the PI3K/Akt pathway and chemotherapeutic resistance. Drug Resist Updat 5: 234-248, 2002

23. Workman P: Inhibiting the phosphoinositide 3-kinase pathway for cancer treatment. Biochem Soc Trans 32: 393-396, 2004.

24. Hu XT and Owens MA: Multiplexed protein quantification in maize leaves by liquid chromatography coupled with tandem mass spectrometry: an alternative tool to immunoassays for target protein analysis in genetically engineered crops. J Agric Food Chem 59: 3551-3558, 2011.

25. Kim O, Jeong Y, Lee H, Hong SS and Hong S: Design and synthesis of imidazopyridine analogues as inhibitors of phosphoinositide 3-kinase signaling and angiogenesis. J Med Chem 54: 2455-2466, 2011.

26. Malumbres M, Pevarello P, Barbacid M and Bischoff JR: CDK inhibitors in cancer therapy: what is next? Trends Pharmacol Sci 29: $16-21,2008$.

27. Semenza GL: Expression of hypoxia-inducible factor 1: mechanisms and consequences. Biochem Pharmacol 59: 47-53, 2000.

28. Shiojima I and Walsh K: Role of Akt signaling in vascular homeostasis and angiogenesis. Circ Res 90: 1243-1250, 2002.

29. Sommers I and Baskin D: Sex, race, age and violent offending. Violence Vict 7: 191-201, 1992.

30. O'Brien C, Wallin JJ, Sampath D, GuhaThakurta D, Savage H, Punnoose EA, Guan J, Berry L, Prior WW, Amler LC, Belvin M, Friedman LS and Lackner MR: Predictive biomarkers of sensitivity to the phosphatidylinositol 3' kinase inhibitor GDC-0941 in breast cancer preclinical models. Clin Cancer Res 16: 3670-3683, 2010.

31. Yang L, Dan HC, Sun M, Liu Q, Sun XM, Feldman RI, Hamilton AD, Polokoff M, Nicosia SV, Herlyn M, Sebti SM and Cheng JQ: Akt/protein kinase B signaling inhibitor-2, a selective small molecule inhibitor of Akt signaling with antitumor activity in cancer cells overexpressing Akt. Cancer Res 64: 4394-4399, 2004.

32. Schultz RM, Merriman RL andis SL, Bonjouklian R, Grindey GB, Rutherford PG, Gallegos A, Massey K and Powis G: In vitro and in vivo antitumor activity of the phosphatidylinositol-3-kinase inhibitor, wortmannin. Anticancer Res 15: 1135-1139, 1995.

33. Rowinsky EK: Targeting the molecular target of rapamycin (mTOR). Curr Opin Oncol 16: 564-575, 2004.

34. LoPiccolo J, Granville CA, Gills JJ and Dennis PA: Targeting Akt in cancer therapy. Anticancer Drugs 18: 861-874, 2007. 
35. Ashe PC and Berry MD: Apoptotic signaling cascades. Prog Neuropsychopharmacol Biol Psychiatry 27: 199-214, 2003.

36. Belozerov VE and Van Meir EG: Hypoxia inducible factor-1: a novel target for cancer therapy. Anticancer Drugs 16: 901-909, 2005.

37. Hamedi M, Wigenius J, Tai FI, Björk P and Aili D: Polypeptideguided assembly of conducting polymer nanocomposites. Nanoscale 2: 2058-2061, 2010.

38. Ben-Shoshan M, Amir S, Dang DT, Dang LH, Weisman Y. and Mabjeesh NJ: 1alpha,25-dihydroxyvitamin D3 (Calcitriol) inhibits hypoxia-inducible factor-1/vascular endothelial growth factor pathway in human cancer cells. Mol Cancer Ther 6: 1433-1439, 2007.

39. López-Lázaro M: Hypoxia-inducible factor 1 as a possible target for cancer chemoprevention. Cancer Epidemiol Biomarkers Prev 15: 2332-2335, 2006.
40. Zhong H, Chiles K, Feldser D, Laughner E, Hanrahan C, Georgescu MM, Simons JW and Semenza GL: Modulation of hypoxia-inducible factor 1alpha expression by the epidermal growth factor/phosphatidylinositol 3-kinase/PTEN/AKT/FRAP pathway in human prostate cancer cells: implications for tumor angiogenesis and therapeutics. Cancer Res 60: 1541$1545,2000$.

41. Mazure NM, Chen EY, Laderoute KR and Giaccia AJ: Induction of vascular endothelial growth factor by hypoxia is modulated by a phosphatidylinositol 3-kinase/Akt signaling pathway in Ha-ras-transformed cells through a hypoxia inducible factor-1 transcriptional element. Blood 90: 3322-3331, 1997.

42. Papetti $M$ and Herman IM: Mechanisms of normal and tumorderived angiogenesis. Am J Physiol Cell Physiol 282: C947-C970, 2002. 